\title{
Anal Fibroepithelial Polyp
}

National Cancer Institute

\section{Source}

National Cancer Institute. Anal Fibroepithelial Polyp. NCI Thesaurus. Code C4435.

A non-neoplastic polypoid lesion that arises from the anal canal or perianal skin. It is

composed of dense fibrous stroma and it is covered by squamous epithelium. 